\title{
0 aparecer da liberdade no pensamento de Hannah Arendt
}

\author{
The Appearance of Freedom in Hannah Arendt's Thought
}

DOI: $10.20873 / \mathrm{rpv} 6 \mathrm{n} 2-13$

\section{Lucas Barreto Dias}

Orcid: 0000-0002-1892-9171

Email: nog_lbd@hotmail.com

\begin{abstract}
Resumo
Este artigo tem como objetivo fazer uma leitura do conceito de liberdade no pensamento de Hannah Arendt a partir da noção de aparência. Para tanto, explico a distinção pela qual a autora entende a originariedade e especificidade da liberdade política frente à liberdade interior (do pensamento e/ou da vontade) e à libertação. Em seguida, desenvolvo o argumento de que o aparecer da liberdade pública possui uma relação de coorigenariedade à política. Nessa perspectiva, o que se destaca é a performatividade da liberdade humana, elemento que remete à virtù maquiaveliana e que confere à liberdade uma dimensão política própria. Se depreende, assim, que o sentido da ação política livre não está subjugado a finalidades ou a causas, mas, sim, à sua própria execução. A liberdade ganha uma dimensão de dignidade mundana e afirma a glória e beleza do agir: a pluralidade humana emerge como condição não apenas da política, mas da liberdade, haja vista sua realização estar intrinsecamente ligada à ação humana plural junto a um mundo comum.
\end{abstract}

\section{Palavras-chave}

Liberdade. Aparência. Pluralidade. Performatividade. Ação. Política.

\begin{abstract}
This paper aims to make an interpretation of the concept of freedom in Hannah Arendt's thought from the notion of appearance. Therefore, I explain the distinction by which the author understands the originality and specificity of political freedom compared to inner freedom (of thought and/or will) and liberation. Then, I develop the argument that the emergence of public freedom has a co-originated relationship with politics. From this perspective, what stands out is the performativity of human freedom, an element that refers to Machiavellian virtù and that gives freedom its own political dimension. Thus, it appears that the meaning of free political action is not subjugated to purposes or causes, but rather to its own execution. Freedom gains a dimension of worldly dignity and affirms the glory and beauty of action: human plurality emerges as a condition not only of politics, but of freedom, given that its realization is intrinsically linked to plural human action in a common world.
\end{abstract}




\section{Keywords}

Freedom. Appearance. Plurality. Performativity. Action. Politics.

\section{Introdução}

Em diversos de seus textos, Arendt critica uma determinada visão da liberdade humana vinculada naturalmente ao indivíduo e que de partida já estaria dada. Esta perspectiva possui diversas raízes na tradição do pensamento político ocidental: por vezes, encontramos discursos sobre a liberdade como uma substância inata à natureza humana e que basta nossa vontade para a atualizarmos; em outros casos, vemos a liberdade como um desenvolvimento histórico proveniente da libertação das amarras político-institucionais em direção a uma afirmação do indivíduo enquanto autor de si mesmo. No decorrer deste texto, ressalto a intrínseca relação que a liberdade guarda com a pluralidade humana, circunstância que irá correlacionar a situação de ser livre como a ação livre junto a outras pessoas. Esta perspectiva pela qual Arendt desenvolve seu argumento nos ajuda a destacar a raiz política da liberdade, bem como sua dimensão performática na medida em que se torna real na medida em que seu campo de experiência é a ação. Junto ao pensamento arendtiano, apresento uma leitura em que destaco importância da noção de aparência para interpretarmos sua teoria política.

Delimito o tema deste artigo, nesse sentido, à leitura do aparecer da política por meio da noção de liberdade. Não me detenho em uma análise exaustiva deste conceito, mas evidencio a importância da virtude e da ação como elementos que se interligam e proporcionam uma compreensão da política como um espaço de aparição plural. Disto, surge o aspecto, por um lado, de uma liberdade que não é expressão de um ego pensante ou volitivo, assim como, por outro, não se limita a uma mera liberdade de movimento. Liberdade, segundo Arendt, provém do mundo, da própria experiência de um espaço no qual cada um pode aparecer aos demais, local em que discurso e ação são experimentados sob diversas perspectivas distintas.

Assim, defendo que em Arendt a existência da liberdade política e a aparição por meio da ação e do discurso são elementos cooriginários, visto que só existe liberdade na medida em 
que ela se manifesta no mundo. Dito isto, o aparecer do espaço público e dos atores políticos só é possível pela fundação da liberdade; de modo análogo, pois cooriginários, a liberdade só é possível pela ação plural em um espaço de aparição. Assim, ganha importância a noção da virtuosidade da ação, a qual ressalta o sentido do agir a partir dele mesmo e não em função de causas e finalidades que lhe sejam exteriores. A beleza da ação se dá a partir de uma dignidade própria da liberdade, a qual proporciona a glória daqueles que agem junto a seus pares em defesa de um mundo comum. 0 aparecer da liberdade pública corresponde à emergência não só da política, mas ao modo pelo qual nos reconciliamos com nossa realidade e dignificamos a existência humana plural.

\section{Liberdade, libertação e liberdade interior}

Hannah Arendt, em A condição Humana (2010a), desenvolve uma leitura da experiência política grega a fim de ressaltar quais aspectos teriam sido paradigmáticos a ponto de constituir o início da própria política ocidental. A compreensão de que os gregos buscavam uma forma de se imortalizar constitui certo pano de fundo histórico sobre tais origens. 0 que Arendt quer destacar aqui se refere, sobretudo, à criação de um espaço capaz de, ao mesmo tempo, preservar a memória dos feitos humanos e de manter a possibilidade de novas ações. $\mathrm{O}$ vir-a-ser do espaço público, assim, teria como prerrogativa ser uma esfera de aparição comum à pluralidade humana, um domínio sem dominação, um local em que os indivíduos se distinguiriam junto a algo que compartilhavam. Além, então, de proporcionar o locus da ação, a pólis seria também responsável por fazer com que as ações realizadas não fossem esquecidas: a cidade imortalizaria seus atores, os cidadãos.

A vida em público, por essa via, seria aquela capaz de fazer perdurar os feitos dos agentes, os quais se imortalizariam por meio da aparência de seus atos; nesse mesmo movimento, a própria cidade seria o espaço em que essa memória seria preservada e, por isso, faria perdurar o sentido da ação dos indivíduos por meio da noção de liberdade (ARENDT, 2010a, pp. 8-25). As ações humanas não são apenas simples resultados de uma natureza que se desenvolve, 
antes, pensa Arendt, há aqui a capacidade humana de iniciar algo novo, de se individualizar por meio da ação, como se o ator nascesse uma segunda vez, agora para o mundo público comum: é aqui que o tema da liberdade passa a figurar na história da humanidade.

Distintamente da tradição filosófica que a precede, Arendt não reduz a liberdade a uma expressão de um eu interior ou simplesmente à liberdade de movimento. Embora por vezes a autora faça menções a estas perspectivas, a sua compreensão da liberdade se move originariamente em outro âmbito, isto é, liberdade é, sobretudo, liberdade política. A libertação ou a liberdade de movimento são condições para a liberdade, mas não se confundem com ela. A liberdade interior (do pensamento e da vontade), por sua vez, seria derivativa da liberdade política. Estas distinções são tema do texto “O que é liberdade?” (ARENDT, 2009, pp. 188-220).

Hannah Arendt diz que o conceito de liberdade sofre uma metamorfose: tendo surgido das experiências políticas gregas, foi dessensorializado e levado à esfera espiritual, sendo entendido pela tradição ${ }^{1}$ como uma expressão da vontade. Arendt defende, no entanto, que a liberdade da vontade só existe derivativamente em relação ao seu sentido político. A experiência das liberdades mundanas - a política e a de movimento - e a subsequente privação delas legounos a busca por uma liberdade no único lugar que ainda poderíamos exercer algum movimento para além das amarras físicas: a esfera mental. Deste modo, como "o fenômeno da liberdade não surge absolutamente na esfera do pensamento" (ARENDT, 2009, p. 191), a autora compreende que a busca por uma liberdade interior advém do fato de o homem ter experimentado inicialmente a liberdade efetivamente política no mundo e, não mais a possuindo, ter se refugiado no pensamento e buscado nessa esfera abstrata um espaço em que possa se chamar de livre. Para Arendt, "as experiências de liberdade interior são derivativas no sentido de que pressupõem sempre uma retirada do mundo onde a liberdade foi negada para uma interioridade na qual ninguém mais tem acesso" (ARENDT, 2009, p. 192), de maneira que "o homem nada saberia da liberdade interior se não tivesse antes experimentado a condição de estar livre como uma

\footnotetext{
${ }^{1}$ Esta tradição teria origem com Paulo, o apóstolo, Agostinho, o bispo de Hipona, e Epicteto, o escravo.
} 
realidade mundanamente tangível" (ARENDT, 2009, p. 194). Deste modo, Arendt não nega a liberdade espiritual, mas a coloca como relativa à existência da liberdade pública.

Assim como não provém do espírito, a liberdade política não se resume também a uma mera liberdade de movimento ou à saciação das necessidades vitais, chamada por Arendt de libertação. No entanto, a liberdade de movimento guarda maior proximidade com a liberdade política do que a liberdade interior. Enquanto esta não é senão uma fuga proveniente da ausência de uma liberdade mundana, aquela guarda estreita relação com a liberdade pública: ela é sua condição, embora não seja causa suficiente, pois a "liberdade [política] (..) era precedida da libertação: para ser livre, o homem deve ter se libertado das necessidades da vida" (ARENDT, 2009, p. 194). Ainda sobre este assunto, em Sobre a revolução, Arendt entende: já que "a libertação (...) é de fato uma condição para a liberdade" (ARENDT, 2011, p. 61), isso significa precisamente que ela é uma preparação para que seja possível a liberdade política, é onde os homens começam a abandonar seu caráter meramente natural suprindo as necessidades que lhe são intrínsecas. É libertando-se das necessidades relativas à vida natural e tornando real sua "liberdade" de movimento que os homens, e não apenas o homem, podem garantir à liberdade política uma realidade concreta.

Para tanto, há um certo abandono do espaço privado no lançar-se à ação pública, de modo que esse abandono momentâneo do lar em vista da individuação e da imortalização pode ser lido também por meio da questão da virtude ${ }^{2}$ e, mais ainda, da liberdade. Não significa, contudo, que o libertar-se das necessidades advindas da privatividade leve inexoravelmente à liberdade política: libertação e liberdade não são expressões similares de uma mesma realidade, pois “a libertação pode ser a condição da liberdade, mas de forma alguma conduz automaticamente a ela" (ARENDT, 2011, p. 57). 0 argumento da pensadora gira em torno do fato de que as duas formas básicas de libertação não são causas suficientes para a liberdade, ainda que sejam, em alguma medida, condições para a ação política livre. Em Sobre a revolução, Arendt nos mostra que o ato de se libertar de um processo de dominação não nos conduz causalmente à

\footnotetext{
${ }^{2}$ Não se trata aqui da noção de virtude ética ou moral, mas pelo sentido atribuído à Maquiavel, isto é, a virtù ator político.
} 
liberdade. Já em A condição humana, Arendt circunscreve que a mera libertação dos afazeres domésticos não nos leva ao agir público. A liberdade política não é compreendida como uma consequência inevitável da libertação, assim, Arendt recusa quaisquer explicações causais da liberdade humana.

A libertação precede a liberdade por meio do liberar-se da necessidade: seja a necessidade proveniente da dominação de servir a um mestre, seja a necessidade de tão somente trabalhar a ponto de não poder se dedicar à vida pública; ainda, em outros termos, seja a necessidade biológica, seja a proveniente das condições econômicas e sociais. A libertação da necessidade, embora surja para Arendt como condição da vida política, foi muitas vezes negligenciada na modernidade filosófica, a qual, segundo Aguiar, "deixou de ligar a política à liberdade para relacioná-la à necessidade" (AGUIAR, 2012, p. 39). Esta ligação entre política e necessidade soa estranha a Arendt pelo fato de a autora compreender que o momento da ação política não é refém do que é necessário, isto é, agir politicamente não é um desenvolvimento natural necessário, assim como não é possível caso o agente esteja sob a dominação ou, ainda, restrito a resolver questões ao âmbito particular e econômico.

A política, antes, diz respeito ao público, ao agir em um espaço que possibilite aos demais verem e ouvirem o que foi feito e dito, a política diz respeito não ao que é privativo, mas ao que é disposto entre a pluralidade humana. No entanto, como já mencionado, a liberdade para agir não provém logo após a libertação, a liberdade requer a coexistência dos homens, ela demanda um espaço em comum em que os seres humanos possam aparecer livremente aos demais. Nesse sentido, Arendt argumenta que a liberdade só é possível quando exercida na "companhia de outros homens que estivessem no mesmo estado, e também de um espaço público comum para encontrá-los (...), no qual cada homem livre poderia inserir-se por palavras e feitos" (ARENDT, 2009, p. 194).

Esta perspectiva se guia por uma concepção na qual os homens não põem como discussão central a vida natural e particular de cada um, mas trazem à tona o mundo comum enquanto aquilo que diz respeito à pluralidade humana, percebendo que esta mesma pluralidade só é possível mediante a compreensão da liberdade política enquanto uma liberdade que não tem 
como fim o domínio sobre outros homens, mas a possibilidade de que cada um se expresse por meio de feitos e palavras no mesmo movimento em que busca garantir a existência de um mundo comum. É na criação artificial de uma esfera capaz de tornar os homens iguais e livres, superando aí o homem em sua mera dimensão natural, que reside a dignidade da política.

A dignidade da política, defendo, não pode ser desvinculada da dignidade da aparência, isto é, nos termos que Arendt usa em $A$ vida do espírito, do valor da superfície. Trata-se, em última instância, de compreender as ações humanas, o mundo comum e os eventos não por meio de uma suposta trama invisível e sobre-humana que conferiria a eles uma realidade autêntica. Em uma postura crítica quanto a isso, Arendt pensa ser justamente a aparência e a pluralidade que tornam possível a vida compartilhada e proporcionam um senso de realidade, pois é o caráter de ser um espaço de aparência que faz com que a esfera política seja permeada de realidade e existência. É nesse sentido que a liberdade, em sua relação indissociável com a política, não pode prescindir da aparência. É o mundo artificial criado pelos homens que possibilita a existência da liberdade, nas palavras de Bernstein: "Sem um âmbito público politicamente, a liberdade carece do espaço público onde aparecer" (BERNSTEIN, 2021, p. 105). A existência da liberdade, portanto, é condicionada à aparência advinda da ação e do discurso: as atividades por meio das quais cada homem faz sua aparição no mundo comum é condição insuperável da liberdade.

Na verdade, poder-se-ia realizar neste ponto uma leitura inversa de que a ação e o discurso só são possíveis mediante a liberdade política, no entanto, parece-nos mais exato a seguinte assertiva: a existência da liberdade política e a aparição por meio da ação e do discurso são cooriginários. Só existe liberdade em sua manifestação, em seu aparecer, e o aparecer do espaço público e do agente só são possíveis pela fundação da liberdade. Não se trata, como se poderia julgar, de um círculo vicioso, mas de um duplo movimento em um só. Trata-se, antes, da inexorável ineliminabilidade da aparência. A dignidade da política e a dignidade da aparência são correlatas a tal ponto que podemos dizer que ambas emergem no mesmo movimento engendrado pela ação e pela liberdade. 
Arendt conjuga liberdade e política de tal maneira que entendo ser possível dizer que o aparecer da liberdade é o aparecer da política. Isto significa que o vir-a-ser do espaço da política é também o devir da liberdade pública. A existência da liberdade, deste modo, pode ser lida por uma chave fenomenológica própria à Arendt: não há uma substância que possamos identificar e chamar de liberdade, antes, na verdade, a liberdade diz respeito às ações humanas, ela existe na medida em que em aparece no mundo, ou, ainda, somos livres quando agimos. Há, portanto, uma perspectiva performática da liberdade no pensamento arendtiano.

\section{0 aparecer da liberdade pública}

Ao ressaltar a dimensão performática da liberdade, não defendo uma unicidade em torno da aparência proveniente da ação, mas destaco o vir-a-ser da liberdade a partir de tal experiência. Concordo, deste modo, com Taminiaux (1999) que não podemos reduzir a política e mesmo a liberdade à performatividade, posto estarmos fadados, caso assim o fizéssemos, a uma mera espontaneidade que parece não fundar nada. Há que se lembrar, nesse sentido, do par novidade-estabilidade: a liberdade se manifesta na ação, mas visa, pensa Arendt, a instituição de um espaço que permita novas aparições. Dito isso, minha pretensão é tão somente compreender como Arendt formula um conceito de liberdade vinculado diretamente ao mundo e à pluralidade humana e que demanda a existência de um espaço de aparição no qual pode ganhar realidade.

A liberdade própria à vida política é relativa às ações humanas que se dão em um espaço público, isto é, um local de aparição em que cada um pode vir a se autoapresentar, nas palavras de Arendt: a "raison d'être da política é a liberdade, e seu domínio de experiência é a ação" (ARENDT, 2009, p. 199). Penso que ao designar a liberdade como razão de ser da política, devemos ter em mente a dupla acepção que o termo destacado pode significar: i) a liberdade como elemento originário da política e ii) a liberdade como finalidade da política. Junto à noção de que o domínio de experiência da liberdade é a ação, o argumento parece circular, pois indica o mesmo elemento como princípio e fim, de modo que soa paradoxal pôr a liberdade como 
condição para o agir político e, ao mesmo tempo, ser algo que se busca alcançar a partir desta mesma ação. 0 problema, todavia, está na imagem causal que dá forma a tal argumento. Não se trata, aqui, de a liberdade causar a política e, na sequência, a política causar a liberdade. A forma, assim posta, procede de um modelo tradicional em que se dispõem os elementos sob uma forma ontológica junto a uma causalidade: algo que se convencionou tanto na metafísica quanto na racionalidade das ciências naturais. Há que se pensar sob um outro paradigma não-tradicional. ${ }^{3}$

A relação entre liberdade e política está circunscrita sob uma mútua aparição: a proveniente do agir. Nesse sentido, a liberdade não é uma substância, é um fenômeno que surge no mundo a partir das ações humanas: é através da ação entre pares que a liberdade aparece e nos tornamos seres políticos. Em vez de um zoon politikon enquanto uma potencialidade inscrita na natureza humana, como se poderia dizer que Aristóteles designava, Arendt pensa que a política - e, portanto, a liberdade - surge entre pessoas que compartilham um espaço comum. É assim que ecoa outra passagem da pensadora: “o homem é apolítico. A política surge entre os homens: portanto, absolutamente fora do homem. Não existe, por conseguinte, nenhuma substância política" (ARENDT, 2010c, p. 146). Essa dupla aparição, no entanto, está fadada a desaparecer: daí que podemos pensar que cabe à pluralidade humana constituir uma esfera perene para a ação, isto é, fundar espaços para que a liberdade volte a surgir. É nesse sentido, penso, que podemos melhor compreender que a liberdade é a razão de ser a política: ambas são mutuamente originárias e a liberdade precisa que, a partir dessa aparição, instituam-se espaços para que ela possa vir novamente a aparecer no mundo.

O espaço público, em Arendt, constitui o espaço da aparência em que cada um pode se fazer ver e ouvir (ARENDT, 2010a, p. 61). Isso só foi possível de ocorrer, segundo a leitura arendtiana, porque na experiência política das póleis gregas a liberdade emergiu como fenômeno

\footnotetext{
${ }^{3}$ Ao dizer que a ação política é uma atividade livre, Arendt indica que uma não adequação seja a motivos, seja a uma finalidade que se intencione alcançar por meio de um efeito previsível, o que significa não que motivos e fins estejam sempre ausentes da ação política, mas que ela é livre para transcendê-los. A interconexão entre liberdade e ação é ainda mais profunda no pensamento de Arendt, pois ao afirmar que a ação deve ser livre para transcender motivos e fins, Arendt quer dizer que ela não é presa a uma cadeia causal que tem como consequência a ação executada, assim como a ação não é guiada pela perspectiva de meio-fim, daí a imprevisibilidade ser uma das características da ação descrita por Arendt em A condição humana.
} 
político sob a forma de isonomia: a igualdade proporcionada pela lei. A intenção que há na criação de um mundo em comum capaz de proporcionar aos homens um espaço onde eles possam aparecer e, com isso, existir e tornar reais a si mesmos e ao próprio mundo, além da imortalização, é de que a desigualdade natural a que todos os homens eram fadados fosse superada. Justamente "porque os homens eram por natureza ( $\varphi$ $\sigma \varepsilon ı)$ não iguais", eles "precisavam de uma instituição artificial, a pólis, que em virtude de seu vó $\mu$ os, os tornaria iguais" (ARENDT, 2011, pp. 58-59). Essa igualdade, porém, não significava meramente a igualdade de condições que provém da libertação, mas a igualdade de partilhar livremente a esfera política. Assim, não podemos simplesmente dizer que o espaço público surge no estar junto dos homens - embora nesse estar junto haja potencialmente uma geração de poder e de um espaço de aparência (Cf. ARENDT, 2010a, pp. 249-259) -, mas depende da fundação de um espaço de liberdade para agir. A liberdade, já no sentido grego, interpreta Arendt, exigia a presença de outros sem a mediação do domínio, demandava que houvesse um espaço de aparência para as atividades humanas, pois estas "apareceriam e seriam reais somente quando fossem vistas, julgadas e lembradas por outros" (ARENDT, 2011, p. 59).

A igualdade entre pares só se tornava real na medida em que era criada artificialmente pelo homem em detrimento da sua mera existência natural e em favor da liberdade. Nesse sentido, a liberdade não é entendida enquanto expressão de uma natureza humana que é atualizada pelo homem na criação da cidade, mas, antes, como a investida do homem contra a sua naturalização na busca de dignidade por aquilo feito através do esforço humano. A isonomia que há no espaço público, portanto, dá forma à liberdade enquanto uma realidade vivenciada entre pares. Ora, a pluralidade humana da qual cada um faz parte ganha contornos políticos na medida em que é qualificada na convivência livre e igualitária, no compartilhamento de um espaço de aparição em que cada um pode ver e ouvir os demais, bem como pode se apresentar a eles. A liberdade, assim, surge na medida em que os seres humanos decidem agir juntos. 
Ação a liberdade, portanto, pressupõem a pluralidade humana ${ }^{4}$, além disso, só existem na medida em que são realizadas, daí Arendt dizer: "o surgimento da liberdade (...) coincide sempre com o ato em realização. Os homens são livres (...) enquanto agem, nem antes, nem depois; pois ser livre e agir são uma mesma coisa" (ARENDT, 2009, p. 199). Isto é o mesmo que dizer: os homens são livres na medida em que fazem seu aparecimento aos outros homens, e esse aparecimento só é feito mediante a ação (e o discurso). Política, liberdade e ação, além de imprescindíveis umas às outras, também não podem prescindir da aparência, pois é na medida em que homens aparecem uns para os outros que eles passam a existir e, mais que isso, tornamse livres e capazes de trazer à realidade um mundo comum: é na esfera da aparência que se funda o próprio domínio político.

Em razão do caráter performático da liberdade pública, Arendt a aproxima da noção de virtuosidade. É relativamente a isso que Étienne Tassin (1989) propõe uma noção de política da aparência em Hannah Arendt. 0 pensador francês ressalta, aqui, a relação que a liberdade guarda não apenas com o espaço público, a ação, a política, a pluralidade, mas com a virtude. ${ }^{5}$ Trata-se, nas palavras de Arendt, da noção de virtuosidade, a qual é "uma excelência que atribuímos às artes de realização (à diferença das artes criativas de fabricação) onde a perfeição está no próprio desempenho e não em um produto final” (ARENDT, 2009, p. 199). Ao afastar a política da fabricação, a pensadora rechaça uma concepção da esfera pública como mera produção humana, como se a política pudesse ser construída de maneira inequívoca. Arendt se aproxima, deste modo, das artes de realização, daquelas ações que não visam necessariamente a fabricação de um produto final, mas encontram sua razão de ser no próprio ato realizado.

Tal como Maquiavel pensou não sob o paradigma do melhor regime, mas pela perspectiva das ações humanas, das circunstâncias mutáveis, da contingência da realidade política,

\footnotetext{
${ }^{4}$ Segundo Arendt, a "pluralidade é especificamente $a$ condição - não apenas a conditio sine qua non, mas a $a$ conditio per quam - de toda vida política" (ARENDT, 2010a, p. 9)

${ }^{5}$ Como paralelo, Tassin pensa que Robespierre representa um contraexemplo quanto à noção de virtude como virtuosidade, na medida em que em vez de uma política da aparência, ele realizaria uma política do coração, a qual nada teria a ver com a liberdade. A base dessa compreensão está ligada ao recurso do revolucionário à virtude moral, fundada na compaixão e na piedade, a qual o conduziria à hipocrisia (cf. TASSIN, 1989, p. 77-82).
} 
Arendt também realiza seu movimento compreensivo a partir das diferentes opiniões que despontam na vida pública compartilhada, das contradições, dissensos e consensos, sem, com isso, esperar por uma síntese final. Inspirada, assim, no conceito de virtù do secretário florentino, Arendt irá refletir sobre a ação política livre junto à noção de virtuosidade, da virtude política enquanto atividade, não como uma qualidade moral.

\section{A beleza da aparência: a virtuosidade da liberdade}

Fiando-se na noção de uma ação livre, Arendt, leitora de Montesquieu, busca no autor de $O$ espírito das leis o conceito de princípio de ação, que distintamente dos motivos - os quais “operam no interior do eu” (ibidem, p. 198) -, não impõe metas, mas inspira a ação. Tais princípios são descritos por Montesquieu em relação às formas de governo, isto é, na orientação e critério para a ação política: “Tais princípios são a honra ou a glória, o amor à igualdade, que Montesquieu chamou de virtude, ou a distinção, ou ainda a excelência - o grego aeí aristeúein (...), mas também o medo, a desconfiança ou o ódio" (ARENDT, 2009, p. 199)ㄷ․ Estes princípios, todavia, só se expressam na medida em que a ação é realizada, isto é, são descritos em termos performáticos tal como a liberdade.

Cabe, aqui, destacar a caracterização arendtiana da liberdade enquanto ação que expressa um tipo de virtude política. Esta formulação de Arendt se vale de uma leitura proveniente de Maquiavel ${ }^{7}$ : a ação não é avaliada nem com base em critérios puramente morais, como também não se reduz a uma mera análise das consequências, mas se vincula ao próprio ato executado. A virtude política enquanto princípio, nesse sentido, deve ser compreendida junto à

\footnotetext{
${ }^{6}$ Ou ainda: "Estes princípios orientadores e critérios da ação, segundo Montesquieu, são, numa monarquia, a honra; numa república, a virtude; e numa tirania, o medo". (ARENDT, 1989, p. 519)

${ }^{7}$ São variados os possíveis temas de encontro entre Arendt e Maquiavel. Delimito, neste espaço, o papel da aparência em ambos os pensamentos políticos a fim de ressaltar o realismo político maquiaveliano e a dignidade da política e da liberdade arendtiana. Quanto à relação entre o pensamento de ambos, Adverse examina os seguintes elementos: 1) o domínio político como mundo da aparência em que os homens podem agir; 2) ao fato de o bem (a bondade) não ser critério para a ação política; 3) a falta de uma finalidade exterior à política. (Cf. ADVERSE, 2008). Ademais, temos também 4) o tema da fundação e da república (Cf. PANCERA, 2013); 5) a questão do Estado e o secularismo; 6) a diferença entre o ator político e o hipócrita; e 6) a compreensão da virtù e da liberdade enquanto componentes da ação política.
} 
noção de aparência, de tal modo que a virtude política também não se reduz a uma mera potencialidade, mas deve sua existência à esfera de aparição, a qual, como visto anteriormente, é composta pela pluralidade humana.

O princípio da ação atua não como causa, mas como inspiração e ganha realidade na medida em que aparece às demais pessoas que compartilham um mundo comum. Isso não implica, por outro lado, em destacar a ação política de suas possíveis consequências, as quais, certamente, merecem ser alvo de reflexão. 0 que se põe em questão é uma avaliação que não se reduza seja a um utilitarismo seja a um dogmatismo quanto a princípios éticos. 0 risco destas duas construções teóricas sobre a realidade subjaz a uma concepção causal das ações humanas (como se elas pudessem ser explicadas tal como se explicam os fenômenos naturais). Esta perspectiva, todavia, pretende encontrar o sentido da ação política fora da esfera do agir: seja em um início que se camufla dos olhos alheios, seja em possíveis consequências que se estendem alhures no tempo e espaço.

O tempo da ação é aquele que se inscreve entre o não mais do passado e o ainda não do futuro, isto é, a temporalidade do agir é aquele do presente e que se mostra publicamente à pluralidade humana. É nessa linha interpretativa que penso ser possível compreendermos a contribuição de Hannah Arendt para o fenômeno da liberdade:

Talvez a melhor ilustração da liberdade enquanto inerente à ação seja o conceito maquiaveliano de virtù, a excelência com que o homem responde às oportunidades que o mundo abre ante ele à guisa de fortuna. A melhor versão de seu significado é "virtuosidade", isto é, uma excelência que atribuímos às artes de realização [performing arts] (à diferença das artes criativas de fabricação), onde a perfeição está na própria realização e não em um produto final que sobrevive à atividade que a trouxe ao mundo e dela se torna independente. (ARENDT, 2009, p. 199; tradução ligeiramente modificada)

O virtuosismo na política, então, não está vinculado aqui a uma fabricação que tem por intenção produzir um objeto distinto dela, mas se refere à sua execução, à sua realização. Se o homem só é livre durante a ação, é nesse executar da ação que ele demonstra sua virtude: a beleza da ação está na sua realização. É no agir que o homem se torna virtuoso e atinge a glória: 
é em como aparece aos outros que reside seu virtuosismo. Mais ainda: é essa pluralidade humana que julgará se tais ações merecem ser imortalizadas. Daí Arendt dizer, em A vida do espírito, que entre os gregos "a virtude humana, o kalon k'agathon [isto é, o belo e bom], não era avaliada pela intenção ou qualidade inata do ator [seus motivos], nem pela consequência de seus atos [a finalidade], mas apenas pela execução, como ele aparecia enquanto estava fazendo" (ARENDT, 2010b, p. 151. Grifos da autora).

A letra de Maquiavel novamente reaparece no sentido que Arendt atribui à ação política, isto porque, como ressalta Helton Adverse, o que está em questão aqui em ambos é a percepção de que "o domínio político (...) é o mundo da aparência, ou ainda da aparição onde cada um pode mostrar quem é" (ADVERSE, 2008, p. 112). Em 1955, como parte de um curso ministrado sobre Teoria Política, há algumas anotações de Arendt sobre Maquiavel para suas aulas, nelas é possível vermos em um dos pontos Arendt sublinhar que para Maquiavel, "o principal conceito da ação política é a glória, que é alcançada pela fortuna e pela virtù", de modo que a "glória brilha", ela é "doxa [aparência, louvor, opinião], aparece, é vista e se faz ver" (ARENDT, 2002, pp. 300-301).

Já nestas anotações podemos verificar que essa virtude tem o sentido do virtuosismo maquiaveliano ligado às artes performáticas/de execução/de realização, isto é, "a política não tem fim mais elevado do que ela própria" (ARENDT, 2002, p. 302). Arendt compreende que o critério aqui para a ação política não está em realizar algum objeto específico, mas no próprio fato de realizar algo. Sua glória está na capacidade de maravilhar seus pares. Esta realização está vinculada a uma compreensão existencial na qual a política e a liberdade só podem existir enquanto performance ${ }^{8}$, ou seja, elas apenas são reais na medida em que aparecem junto à

\footnotetext{
${ }^{8}$ Isto está em conformidade com a conhecida diferenciação que ela faz entre o político e o social. Não é que certos temas sejam exclusivamente sociais ou políticos, mas, sim, que alguns conteúdos podem ter tanto um tratamento do ponto de vista social quanto político. Arendt oferece o exemplo do problema da moradia: "O problema social é certamente uma moradia adequada, mas a questão sobre se esta moradia adequada significa integração ou não é certamente uma questão políticas. Em cada uma destas questões há uma dupla face, e uma destas faces não deve estar sujeita a discussão [isto é, a social, a que pode ser resolvida por técnicos, a que é calculável]. Não deveria haver qualquer debate sobre a questão acerca de se todos devem ter uma moradia decente". (ARENDT, 2010c, p. 141)
} 
pluralidade, em que as circunstâncias do ver e ser visto / ouvir e ser ouvido proporcionam realidade à ação humana.

Aparência, beleza e glória conferem à ação política livre uma dimensão de dignidade própria que não lhe seria possível caso a subsumíssemos aos critérios de avaliação causal. É através da ação que o ator político pode vir a aparecer e ser objeto de contemplação, é em performance que ele demonstra seu virtuosismo e faz surgir a beleza e a glória. Nenhum destes é um produto, são intangibilidades que surgem e se esvaem com o próprio agir. Se perduram, é porque tornaram-se estórias, tal como Aquiles é lembrado por Homero, o qual encontra um modo de manter o brilho da aparência de seus feitos, assegurando a glória para a posteridade. Só por meio do aparecer, do surgir no mundo pela performance, que se é possível a criação de um mundo: funda-se e conserva o espaço público, o local de aparição da liberdade que na mesma medida em que deve ser conservado, deve também dar espaço ao novo.

É por isso que, segundo Arendt, “Maquiavel não pergunta jamais: para que serve a política?", pois estava ciente de que "a política não tem fim mais elevado do que ela própria" (ARENDT, 2002, p. 302). Assim como não tem um fim externo a ela, não tem também um fundamento externo: não são virtudes morais ou qualidades religiosas que lhe conferem beleza e glória, mas o próprio fato de aparecerem aos demais. É o regozijo no próprio agir que lhe proporciona a felicidade pública, é sua execução que lhe garante realidade, pois não se restringe ao espaço privado, antes, é pública e mundana, disposta à pluralidade e condicionada por ela. A política é, portanto, mundana e secular, sua dignidade provém não de um fundamento ontológico-metafísico, mas por estar inserida na realidade fenomênica, por existir e ter significado apenas entre os homens. Nesse sentido, parece-me que a dignidade da política de Arendt e o realismo político de Maquiavel reportam sempre a um ponto em comum: a dignidade e realidade da aparência.

A beleza e glória advindas da ação só são possíveis mediante sua qualidade de serem aparências e, com isso, pressupor espectadores que assistem e julgam as ações, que as transformam em estórias e as inserem na história. 0 que é narrado são os "grandes feitos e grandes palavras" que, para além de se tornarem um poema de Homero, buscam algo ainda mais digno: 
a política. É esse o sentido da pólis: "estabelecer e manter em existência um espaço em que a liberdade, enquanto virtuosismo, pudesse aparecer. É este o âmbito em que a liberdade constitui uma realidade concreta" (ARENDT, 2009, p. 210) e para tanto "os feitos humanos tinham que "brilhar por seus méritos intrínsecos'” (ARENDT, 2010b, p. 151). É a aparência - o vir-aser no mundo comum e plural, bem como a criação de espaços de aparição, isto é, espaços públicos - que pode dar realidade e dignidade à liberdade, à política e a todo o seu conjunto de termos e conceitos.

\section{Referências bibliográficas}

ADVERSE, Helton. Maquiavel: Política e retórica. Belo Horizonte: Editora UFMG, 2009.

. "Política e Aparência. Hannah Arendt leitora de Maquiavel”. Síntese, v. 35, n. 111, 2008.

AGUIAR, Odilio. Necessidade e liberdade em Hannah Arendt. Princípios: Revista de Filosofia (UFRN), v. 19, n. 32, p. 35-54, 14 jul. 2015.

ARENDT, Hannah. A condição humana. Trad. Br.: Roberto Raposo, revisão técnica: Adriano Correia. 11ª edição. Rio de Janeiro: Forense Universitária, 2010a.

_. Entre o passado e o futuro. Trad. br.: Mauro W. Barbosa. 6aㅡ ed. São Paulo: Perspectiva, 2009.

"Notas sobre a Política e o Estado em Maquiavel". Trad. de G. Cohn a partir da tradução francesa de M. Gaille-Nikodimov. Lua Nova, no 55-6, 2002, pp. 298-302.

_. Origens do totalitarismo: anti-semitismo, imperialismo, totalitarismo. Trad. br.:

Roberto Raposo. São Paulo: Companhia das Letras, 1989.

_. A promessa da política. Trad. Br. De Pedro Jorgensen Jr. 3a Edição. Rio de Janeiro: Difel, 2010c.

. Sobre a revolução. Trad. Br. de Denise Bottmann. São Paulo: Companhia das letras, 2011.

. "Sobre Hannah Arendt". Trad. de Adriano Correia. Inquietude, v. 1, no 2, ago/dez - 2010d.

. A vida do espírito: o pensar, o querer, o julgar. Trad. br.: Cesar Augusto R. de Almeida, Antônio Abranches e Helena Franco Martins. 2 ${ }^{\underline{a}}$ ed. Rio de Janeiro: Civilização Brasileira, 2010b.

BERNSTEIN, Richard. Por que ler Hannah Arendt hoje? Trad. Br.: Adriano Correia e Nádia Ribeiro. Rio de Janeiro: Forense Universitária, 2021.

MAQUIAVEL, Nicolau. O príncipe. Edição bilíngue. Trad. br. de José Antônio Martins. São Paulo: Hedra, 2011.

PANCERA, Gabriel. "Arendt e Maquiavel: fundação, violência e poder no pensamento republicano". Argumentos, ano 5, n. 9 - Fortaleza, jan./jun. 2013.

TAMINIAUX, Jacques. "Performativité et Grécomanie?”. Revue Internationale de Philosophie, Paris, vol. 53, no 208, p. 191-207, février 1999, p. 191-205. Disponível em: https://www.jstor.org/stable/23955551?read-now=1\&seq=1\#page_scan_tab_contents. Acesso em: 17 de novembro de 2021. 
TASSIN, Étienne. "La question de l'apparence". In : ABENSOUR, Miguel. Ontologie et Politique : actes du Colloque Hannah Arendt. Éditions Tierce, 1989.

Recebido em: $17 / 11 / 2021$

Aprovado em: 05/12/2021

\section{Lucas Barreto Dias}

Professor do Instituto Federal de Educação, Ciência e Tecnologia do Ceará - IFCE, campus Fortaleza. Docente do quadro permanente do Curso de Mestrado Acadêmico em Filosofia da Universidade Estadual do Ceará UECE. Doutor em Filosofia (Ética e Filosofia Política) pela UFMG, com tese sobre "Os métodos de Hannah Arendt". Mestre em Filosofia (Ética e Filosofia Política) pela UFC, com dissertação sobre "O conceito de aparência no pensamento de Hannah Arendt". Possui graduação em Licenciatura plena em Filosofia pela Universidade Estadual do Ceará (UECE) com monografia sobre Ontologia, política e moral em Simone de Beauvoir. Membro do GT de Filosofia Política Contemporânea da ANPOF. Membro do grupo de pesquisa CENTELHA, do IFCE. Membro e pesquisador do GEPEDE - UVA. Membro e pesquisador do grupo de pesquisa Ética e Filosofia política - UFC. Áreas e temas de interesse na Filosofia: Filosofia Política, Ética, Existencialismo, Hermenêutica e Fenomenologia. Desenvolvendo pesquisa sobre a relação entre método e pensamento político a partir de Hannah Arendt, bem como sobre a relação entre política e formas de dominação. Realizando projeto sobre a relação entre Filosofia, Matemática e o Método científico. À frente do podcast de filosofia Ágora café. 